\title{
Effect of immediate implant placement and loading on soft tissue management
}

\author{
Erdem Özdemir ${ }^{1 *}$, Yener Oguz ${ }^{2}$ \\ ${ }^{1}$ Metin Kasapoğlu Caddesi, Yeşilbahce Mah. No: 59/9 PK. 07160 Muratpaşa, Ankara, Turkey \\ ${ }^{2}$ Department of Oral Maxillofacial Surgery, Dentistry Faculty, Baskent University, Ankara, Turkey \\ Email: dnterdem@gmail.com
}

Received 11 August 2013; revised 21 October 2013; accepted 28 October 2013

Copyright (C) 2013 Erdem Özdemir, Yener Oğuz. This is an open access article distributed under the Creative Commons Attribution License, which permits unrestricted use, distribution, and reproduction in any medium, provided the original work is properly cited.

\begin{abstract}
The recent article describes immediate implant placement and loading in the anterior segment. The main aim of this treatment option was to deliver provisional prosthesis to the patient in the same day of surgery, form papilla contours, and eliminate waiting of osseointegration time and the second surgery.
\end{abstract}

Keywords: Immediate Implant Placement; Provisional Denture; Papilla Forming

\section{INTRODUCTION}

Traditionally, when incisors are lost in the anterior maxilla, canines/premolars-supported fixed partial denture is the mandatory treatment option. The number of lost teeth, the length of the arch, and the mobility of the abutment teeth should be carefully considered before deciding the number of abutments [1]. Furthermore, fixed partial dentures in the anterior maxilla cause increased bending forces than the anterior mandibula because of the larger curve. In case all maxillary incisors are lost, the pontics will lie outside of the inter-abutment axis line and the forces will act as a lever arm that operates the torquing forces on the canines/premolars [1]. In such cases, implant treatment options, which also eliminate the preparation of teeth, become a viable treatment option for patients [2].

Teeth loss will decrease the bone level of the extraction site and the surrounding soft tissue volume [3], with significant tissue loss in the first month; this will keep decreasing for at least six months [4]. In the healed sites, because of decreased bone height, shorter implants can be placed and longer crowns should be designed because of the lost soft and hard tissues. This short-implant/ long-crown combinations can face some mechanical problems and result in bone resorption, which can cause implant failure. The loss of soft tissue will result in lost interdental papillae. Interdental papillae loss will also affect the esthetic configuration [5] - "black triangle" areas that affect the esthetic dental harmony which can be observed between the crowns [6]. The lack of interdental papillae will also result in phonetic problems and food impaction [6].

Immediate implant placement terminology describes implant placement following tooth extraction immediately into extraction cavity. Immediate implant placement has favorable outcomes [7] — decreasing the treatment time, decreasing the number of surgeries, and decreasing the risk of hard and soft tissue resorption $[8,9]$. In other words, it was shown that immediate implant placement at the extraction sites preserves the bone and soft tissue volume [10-12]. In the cases, primary stability can be observed, and immediate loading protocol can be executed in the anterior sites. At least a $32-35 \mathrm{Ncm}$ torque is required for the single implants' immediate loading [13,14]. Mozatti et al. [15] showed in their retrospective study that immediate implant placement and loading have successful long-term results as compared to delayed implant loading. Juodzbalys and Wang [16] placed implants into extraction sockets and followed for one year. They found that the implant success rate was $100 \%$ and the keratinize soft tissue volume was sufficient with $92.9 \%$.

Immediate implant placement and delivery of provisional crowns in the same day of surgery provide immediate comfort to the patients, keep the teeth in place and support the lip [17]. Following extraction, immediate implant placement and loading support the hard and soft dental tissues at the extraction sites $[18,19]$. Provisional crowns maintain and reshape the soft tissue contours during healing [20]. Di Alberti et al. [21] showed in their study that immediate implant loading in the anterior maxilla preserves the interdental papillae and supports the soft tissue contours. In another study, it was shown that immediate implant placement and loading main- 
tained the papillae and peri-implant soft tissue contours. [22] However, it is known that esthetics can be improved by conditioning the area beneath the pontic that is predicated on convex shape and applying positive pressure [14,23].

This article describes immediate implant placement and loading in the anterior maxilla following extractions of maxillary incisors. At two different times, provisional fixed partial dentures were fabricated; the first one was finished immediately after surgery and the second one was produced at a dental laboratory after the sutures were removed. The aims of provisional restorations were achieving a positive pressure on the soft tissue and reshaping it to the new esthetic configuration.

\section{CLINICAL REPORT}

A 52-year-old woman presented to the Prosthodontics department of Baskent University Umitköy Clinic with esthetic problems related to the maxillary anterior region; she had also lost her maxillary first, second and mandibular first molars. There was a fixed partial denture that was supported with maxillary incisors for about seven years. The patient had gingival problems, such as bleeding, and was also unhappy with the smell and the view of "black triangles" between the crowns (Figure 1). After inspection and radiographic evaluation of teeth (Figure 2), it was seen that the surrounding bone levels of the central and lateral incisors were decreased. Imme-

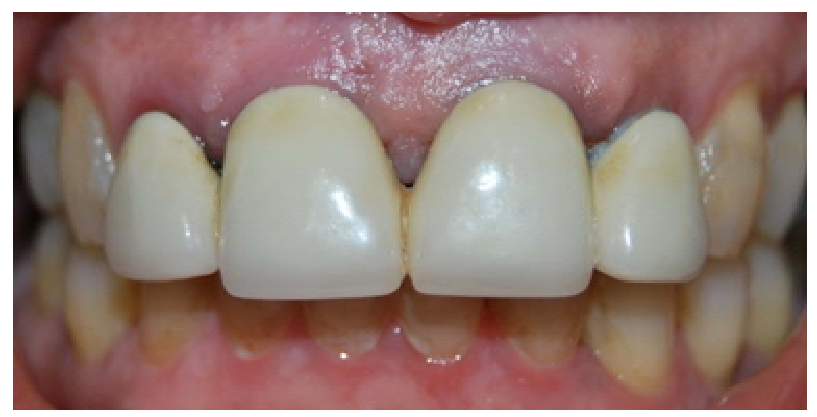

Figure 1. The intraoral view of teeth before the treatment.

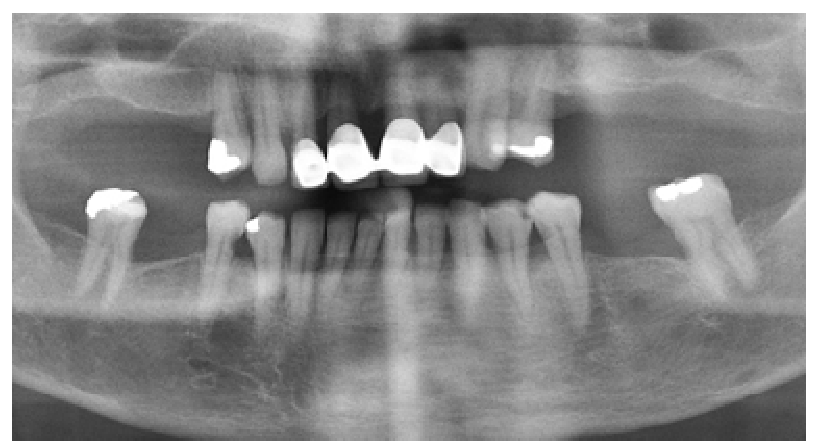

Figure 2. The panoramic radiograph of patient before implant placement. diate implant placement and loading after the incisors' extraction and placing implants for the first and second molars in the maxillary and tooth-supported fixed partial denture for the mandibular posterior site was recommended to the patient. The treatment options were accepted by the patient. A maxillary impression was taken with an irreversible hydrocolloid material (Blueprint Cremix; Dentsply DeTrey, GmbH, Konstanz, Germany) and poured with Type IV dental stone (Amberok; Anadolu Dental Products, Istanbul, Turkey) to obtain a stone model. A sheet of 0.0035-inch-thick bleaching tray material (Regular Soft-Tray, 0.0035 inch; Ultradent Products, Inc) in the forming frame of the vacuum machine (UltraVac Vacuum Former; Ultradent Products, Inc) was fixed to the stone model to fabricate the provisional denture after implant placement. The central and lateral incisors in the anterior maxillary were extracted, the buccal plates of the extraction sockets were preserved, and two dental implants were placed into the extraction sockets of the lateral incisors (Tapered Screw-Vent; 3.7 $\mathrm{mm} \times 12 \mathrm{~mm}(\mathrm{TSVB}), 4.1 \mathrm{~mm} \times 12 \mathrm{~mm}(\mathrm{TSV} 4 \mathrm{~B})$, Zimmer Dental Inc.). A torque of at least $30 \mathrm{Ncm}$ was obtained with a torque wrench (TW 30, Zimmer Dental Inc.) and after immediate placement, primary stability was controlled with horizontal and rotational movements of the implants. The extraction sockets of the central incisors were sutured with bioresorbable material (Vicryl 4.0 polyglactin 910; Johnson \& Johnson Intl, St. Stevens, Woluwe, Belgium). Temporary abutments (HLPT Hex-Lock Plastic Temporary Abutment, Zimmer Dental Inc.) were mounted (Figure 3) to the implants and an open tray impression was taken by using a polyether silicone material [24,25] (Impregum Penta Soft, $3 \mathrm{M}$ Espe, St Paul, Minn.). Following the impression, the implant analogs (Implant analog, IA3, Zimmer Dental Inc.) were mounted to the temporary abutments and the impression was poured with a Type IV dental stone (Amberok; Anadolu Dental Products, Istanbul, Turkey). The areas that would be beneath the pontics on the model, were scraped to $1 \mathrm{~mm}$ and the temporary abutments were prepared. The anterior incisors of the sheet material was filled with auto-polymerizing acrylic resin (Protemp 3, Temporization Material, 3M Espe, St Paul, Minn) and

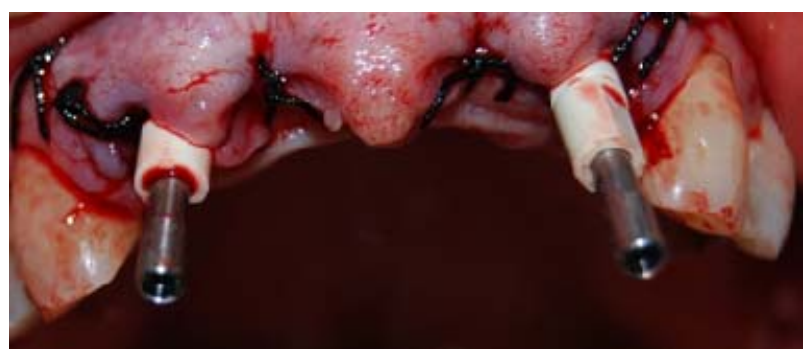

Figure 3. Provisional abutments were placed before taking impression, following immediate implant placement. 
seated on to the model; just before the polymerization finished, the sheet material was removed. Following the polymerization of the acrylic resin, the provisional denture removed from the sheet material. The abutments were then transferred to the mouth, as in the model, and the provisional denture was adjusted to the abutments. Provisional cement (TempBond Clear; Kerr Corporation, Orange, $\mathrm{Ca}$ ) was mixed and loaded into the provisional crowns; these provisional crowns were placed on to the abutments and just before the setting of the cement, the provisional denture was removed, the excess cement was cleaned around the abutments/crowns, and the provisional denture was placed again. Pontics applied a positive pressure on the soft tissue (Figure 4).

One week after surgery, the provisional denture and sutures were removed. The transfer posts (Fixture mount, replacement retaining screw, FMT3, Zimmer Dental Inc.) were remounted on to the implants and an impression was taken with polyether silicone material. The casts were articulated in a semiadjustable articulator (Protar Evo 2; Kavo, Biberbach, Germany) and an interocclusal centric relation record. The temporary abutments were remounted on to the maxillary cast and the new provisional fixed partial denture was produced in the laboratory with auto-polymerizing acrylic resin (Jet Set-4, Lang Dental Mfg. Co. Inc., Wheeling, Ill), according to the healed soft tissue areas. During the six months of osseointegration, the patient was followed with recall appointments every two months, and at every appointment, the provisional denture was removed and adjusted according to the healed soft tissue areas, polished, and recemented. Oral hygiene instructions were given to the

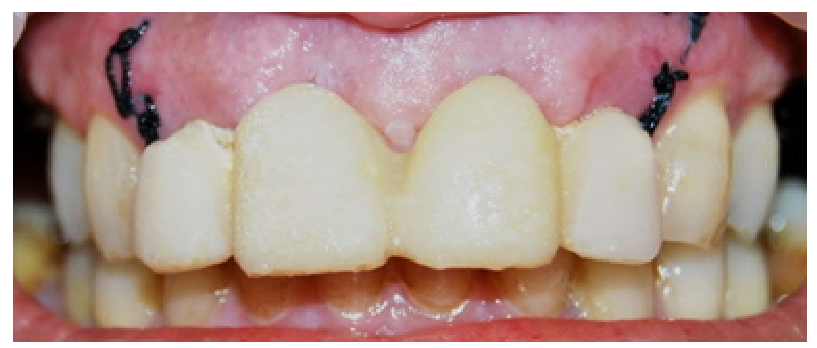

(a)

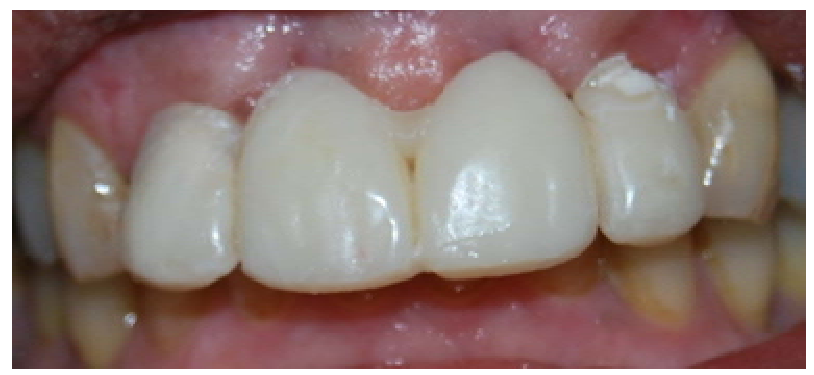

(b)

Figure 4. The provisional denture is in place. This view was obtained after 1 week of implant placement. patient, which included tooth brushing and daily flossing. At the six-month follow-up appointments, a panoramic radiograph was taken (Figure 5) and intraoral examination was geminated, no complications were noted. The provisional denture was removed and the soft tissue had healed and matured with adequate volume (Figure 6). The transfer posts (Fixture mount, replacement retaining screw, FMT3, Zimmer Dental Inc.) were mounted to the implants and a closed-tray impression was taken with the addition of silicone (Express; 3M ESPE, St Paul, Minn.). An elastomeric material for gingival reproduction (Gi-Mask, Coltene/Whaledent) was injected around the impression and implant analogs (Implant analog, IA3, Zimmer Dental Inc.) were assembled to transfer posts before obtaining the model. An irreversible hydrocolloid impression (Blueprint Cremix; Dentsply De Trey, GmbH, Konstanz, Germany) was made of the opposing mandibular dentition. The casts were articulated in a semiadjustable articulator (Protar Evo 2; Kavo, Biberbach, Germany) with facebow transfer and an interocclusal centric relation record.

Prefabricated abutments (Hex-lock contour abutments, straight, MHLAS, Zimmer Dental Inc.) were selected and prepared. The metal coping for the definitive restoration was fabricated with base metal alloy (Wiron 99, composition\%: Ni: 65, Cr: 22.5, Mo: 9.5, Si: 1, Nb: 1, Fe: 0.5, Ce: 0.5, C: max. 0.02; Bego Dental). Low fusing porcelain (Omega 900; VITA Zahnfabrik) was applied to the metal coping. The definitive crown was evaluated

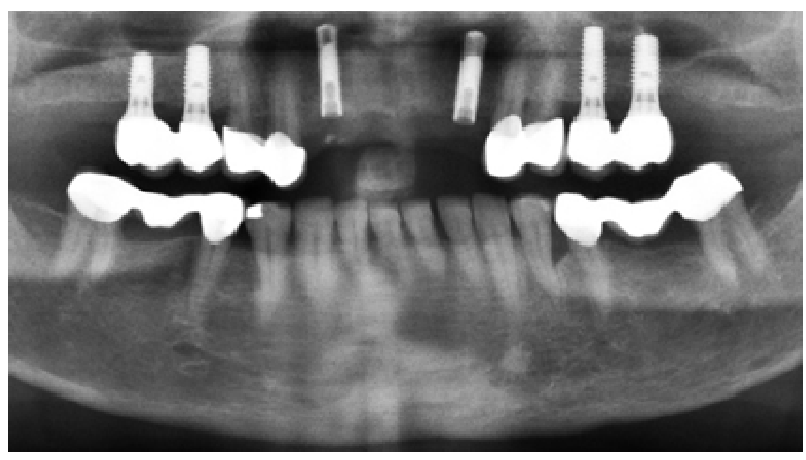

Figure 5. Panoramic radiograph after implant placement.

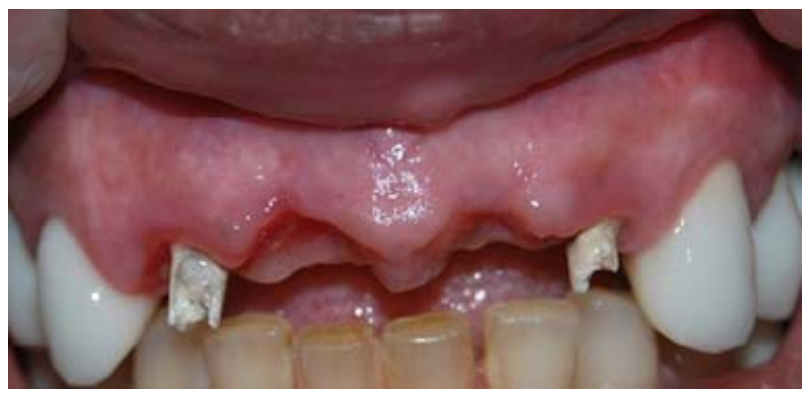

Figure 6. Healed interproximal soft tissue was matured and demonstrated adequate volume. 
intraorally and proper occlusion was achieved. The definitive crown was cemented with glass ionomer cement (Ketac Cem; 3M ESPE) (Figure 7).

\section{DISCUSSION}

Immediate implant placement and loading have gained popularity in the rehabilitation of the anterior maxilla. Shortening the time period and eliminating second-stage surgery, delivering provisional dentures to the patient in the same day of surgery, contouring and creating the soft tissue are some of the benefits of immediate implant placement and loading, compared to the conventional implant treatment methods [5]. Usually anterior segments (between premolars) should be selected for immediate implant placement and loading. In the present clinical report, the maxillary anterior incisor teeth were extracted and two implants were placed into the lateral teeth extraction sockets and loaded in the same day of surgery.

In the present case, soft tissue loss around the crowns (Figure 1) and decreased bone heights around the roots belonging to the maxillary incisors (Figure 2) can be seen. Extracting the incisors and waiting for the healing period before implant placement would cause an increase in bone and soft tissue resorption. This will affect the implant and crown lengths. As mentioned before, short-implant and long-crown combinations will result in mechanical risks and an unaesthetic view. It was reported that implants placed in extraction sockets have similar outcomes as placement in healed sites [5]. For healing site implant placement, 4 - 6 months are needed for osseointegration after the healing of extraction sockets [8]. Alternative provisional dentures for the anterior regions at the time of osseointegration were described earlier, such as removable partial dentures and resin-bonded fixed partial dentures [7,14]. But a removable partial denture is not usually a tenderness choice for patients and resin-bonded fixed partial denture is not convenient for the loss of four teeth in the anterior maxilla; therefore, immediate loading is beneficial to patient satisfaction. However, provisional crowns can create soft tissue con-

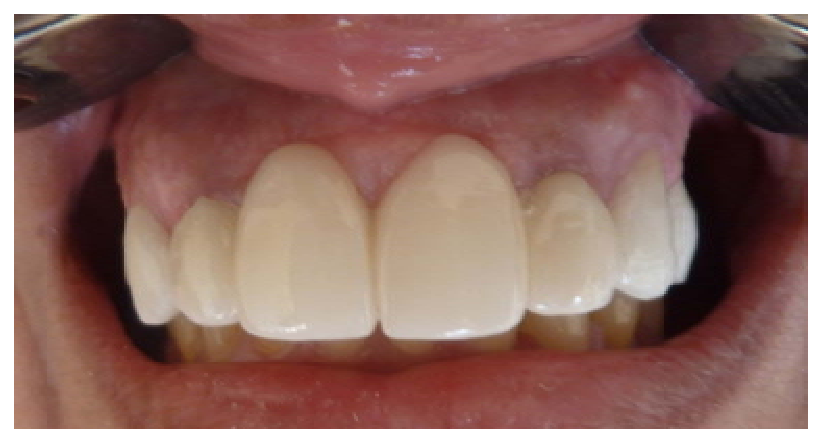

Figure 7. Definitive crowns in place. tours by applying pressure [14]. Jacques et al. [20] described a technique for the improvement of soft tissue beneath the pontics by applying pressure. It is recommended that 3 - $5 \mathrm{~mm}$ soft tissue thickness is required to reshape by applying pressure [20]. In the present case, it is clearly seen that after the extraction of teeth, the papillae between the extracted central and soft tissues around the extracted areas are enough to form by applying pressure (Figure 3). Polyether impression material was preferred to obtain a detailed and nonfunctional soft tissue impression [24]. Polyether is a flowable impression material that under pressure displaces the soft tissue minimally at the time of taking the impression [25]. In the present case, the provisional denture was delivered in the same day of extraction and is more effective in shaping the soft tissue contour and the interdental papillae during healing. Chen and Buser [17] evaluated the aesthetic outcomes of implants placed in the extraction sites, and according to their review, midfacial recession after the immediate implants is a higher risk (more than 1 $\mathrm{mm}$ ). However, Cosyn et al. [2] found papillae regrowth and a low risk for advanced midfacial recession. This result is also similar to Block et al.'s and Van Kasteren et al.'s results $[18,19]$. These contrast findings may be the result of gingival biotype selection. A thin gingival biotype can be the cause of midfacial recession. In a recent case, the gingival biotype of the patient was an example of thick-flat gingival biotype, which was classified by De Rouck et al. [12], and is more resistant to recession after implant placement. A criticism for the present case is the cemented provisional restorations. Immediately following the cementing of the provisional restoration, it was removed, the excess cement was cleaned, and the restoration placed back. The interposing of the cement into the gingival sulcus was interrupted.

\section{REFERENCES}

[1] Shillinburg, H. T. (2007) Fundamentals of fixed prosthodontics. 6th Edition, Quintessence, 95.

[2] Cosyn, J., Eghbali, A., De Bruyn, H., Collys, K., Cleymaet, R. and De Rouck, T. (2011) Immediate singletooth implants in the anterior maxilla: 3-year results of a case series on hard and soft tissue response and aesthetics. Journal of Clinical Periodontology, 38, 746-753. http://dx.doi.org/10.1111/j.1600-051X.2011.01748.x

[3] Choquet, V., Hermans, M., Adriaenssens, P., Daelmans, P, Tarnow, D.P. and Malevez, C. (2001) Clinical and radiographic evaluation of the papilla level adjacent to single-tooth dental implants. A retrospective study in the maxillary anterior region. Journal of Periodontology, 72, 1364-1371.

http://dx.doi.org/10.1902/jop.2001.72.10.1364

[4] Van der Weijden, F., Dell'Acqua, F. and Slot, D.E. (2009) Alveolar bone dimensional changes of post-extraction 
sockets in humans: A systematic review. Journal of Clinical Periodontology, 36, 1048-1058. http://dx.doi.org/10.1111/j.1600-051X.2009.01482.x

[5] Gökçen-Röhlig, B., Meriç, U. and Keskin, H. (2010) Clinical and radiographic outcomes of implants immediately placed in fresh extraction sockets. Oral Surgery, Oral Medicine, Oral Pathology, Oral Radiology, 109, e1e7

[6] Chow, Y.C. and Wang, H.L. (2010) Factors and techniques influencing peri-implant papillae. Implant Dentistry, 19, 208-219. http://dx.doi.org/10.1097/ID.0b013e3181d43bd6

[7] Boff, L.L., Oderich, E., Cardoso, A.C. and Magne, P. (2010) Retrofitting a tooth-supported crown with an implant and abutment: A clinical report. Journal of Prosthetic Dentistry, 103, 262-266. http://dx.doi.org/10.1016/S0022-3913(10)00068-5

[8] De Rouck, T., Collys, K. and Cosyn, J. (2008) Singletooth replacement in the anterior maxilla by means of immediate implantation and provisionalization: A review. International Journal of Oral \& Maxillofacial Implants, 23, 897-904.

[9] Chen, S.T., Darby, I.B., Reynolds, E.C. and Clement, J.G. (2009) Immediate implant placement postextraction without flap elevation. Journal of Periodontology, 80, 163-172. http://dx.doi.org/10.1902/jop.2009.080243

[10] De Rouck, T., Collys, K. and Cosyn, J. (2008) Immediate single-tooth implants in the anterior maxilla: A 1-year case cohort study on hard and soft tissue response. Journal of Clinical Periodontology, 35, 649-657. http://dx.doi.org/10.1111/j.1600-051X.2008.01235.x

[11] De Rouck, T., Collys, K., Wyn, I. and Cosyn, J. (2009) Instant provisionalization of immediate single-tooth implants is essential to optimize esthetic treatment outcome. Clinical Oral Implants Research, 20, 566-570.

[12] De Rouck, T., Eghbali, R., Collys, K., De Bruyn, H. and Cosyn, J. (2009) The gingival biotype revisited: Transparency of the periodontal probe through the gingival margin as a method to discriminate thin from thick gingiva. Journal of Clinical Periodontology, 36, 428-433. http://dx.doi.org/10.1111/j.1600-051X.2009.01398.x

[13] Wang, H.L., Ormianer, Z., Palti, A., Perel, M.L., Trisi, P. and Sammartino, G. (2006) Consensus conference on immediate loading: The single tooth and partial edentulous areas. Implant Dentistry, 15, 324-333. http://dx.doi.org/10.1097/01.id.0000246248.55038.3a

[14] Ozdemir, E., Lin, W.S. and Erkut, S. (2012) Management of interproximal soft tissue with a resin-bonded prosthesis after immediate implant placement: A clinical report. Journal of Prosthetic Dentistry, 107, 7-10. http://dx.doi.org/10.1016/S0022-3913(12)60008-0
[15] Mozzati, M., Arata, V., Gallesio, G., Mussano, F. and Carossa, S. (2012) Immediate postextraction implant placement with immediate loading for maxillary full-arch rehabilitation: A two-year retrospective analysis. The Journal of the American Dental Association, 143, 124133.

[16] Juodzbalys, G. and Wang, H.L. (2007) Soft and hard tissue assessment of immediate implant placement: a case series. Clinical Oral Implants Research, 18, 237-243. http://dx.doi.org/10.1111/j.1600-0501.2006.01312.x

[17] Chen, S.T. and Buser, D. (2009) Clinical and esthetic outcomes of implants placed in postextraction sites. International Journal of Oral \& Maxillofacial Implants, 24, 186-217.

[18] Block, M.S., Mercante, D.E., Lirette, D., Mohamed, W., Ryser, M. And Castellon, P. (2009) Prospective evaluation of immediate and delayed provisional single tooth restorations. International Journal of Oral \& Maxillofacial Implants, 67, 89-107. http://dx.doi.org/10.1016/j.joms.2009.07.009

[19] van Kesteren, C.J., Schoolfield, J., West, J. and Oates, T. (2010) A prospective randomized clinical study of changes in soft tissue position following immediate and delayed implant placement. International Journal of Oral \& Maxillofacial Implants, 25, 562-570.

[20] Al-Harbi, S.A. and Edgin, W.A. (2007) Preservation of soft tissue contours with immediate screw-retained provisional implant crown. Journal of Prosthetic Dentistry, 98, 329-332. http://dx.doi.org/10.1016/S0022-3913(07)60107-3

[21] Di Alberti, L., Donnini, F., Di Alberti, C., Camerino, M., Sgaramella, N. and Lo Muzio, L. (2012) Clinical and radiologic evaluation of 70 immediately loaded single implants in the maxillary esthetic zone: Preliminary results after 1 year of functional loading. International Journal of Oral \& Maxillofacial Implants, 27, 181-186.

[22] Christian, J., Grover, M. and Thallam Veeravalli, P. Replacement of mandibular posterior teeth with implants in a post mandibular resection case-A case report. Journal of Oral Implantology, 2011.

[23] Jacques, L.B., Coelho, A.B., Hollweg, H. and Conti, P.C. (1999) Tissue sculpturing: An alternative method for improving esthetics of anterior fixed prosthodontics. Journal of Prosthetic Dentistry, 81, 630-633. http://dx.doi.org/10.1016/S0022-3913(99)70221-0

[24] Pratten, D.H. and Novetsky, M. (1991) Detail reproduction of soft tissue: A comparison of impression materials. Journal of Prosthetic Dentistry, 65, 188-191. http://dx.doi.org/10.1016/0022-3913(91)90160-X

[25] Polyether Imression Material, Technical Product Profile, 3M ESPE. 